\title{
DIGITAL DIVIDES AND THE ROLE OF POLICY AND REGULATION: A QUALITATIVE STUDY
}

\author{
Panayiota Tsatsou \\ London School of Economics and Political Science, UK
}

\begin{abstract}
This chapter aims to answer the research question: what is the role of internet policy and regulation in digital divides in Greece? I argue that Internet policy and regulation account significantly for the persistence of digital divides in Greece. The chapter draws on literature that views the role of policy and regulation in digital inclusion as problematic and proposes a more dialectical view of the interactions between politics and technology, so that the democratic and participatory potential of the Information Society can be approached more critically. The chapter explores the research question empirically through in-depth individual interviews with elite actors in the Greek Information Society. Elite actors who are involved in various areas of policy and regulation in the Greek Information Society are in the position to account for the role of internet policy and regulation in aspects of digital exclusion from more than one perspective. Thus, the chapter argues about the significant role of decision-making in the Greek case of digital divides, providing the grounding upon which research outside Greece could rely on to look at other cases of digital divides and at the role of policy and regulation accordingly.
\end{abstract}

Keywords: Digital divides, Greece, policy, regulation, interviews

\section{Introduction}

This chapter reports on ongoing research into digital divides in Greece. The part of the research reported here examines factors of influence for digital divides in Greece which operate at the level of decision-making. The central question addressed is: what is the role of Internet policy and regulation in digital divides in Greece?. It is argued that Internet policy and regulation frameworks account significantly for the persistence of digital divides in Greece.

Although other forces such as social psychology, economics, technology design, and innovation parameters could be considered in researching digital divides, this chapter looks at decision-making on policy and regulation in order to explore specific aspects of digital divides in Greece. The emphasis is grounded in 
the interest that decision-making discourses and practices present for understanding and explaining the case of Greek divides, as briefly illustrated later in the chapter.

In what follows, the conceptual and research foundations of the work are established and the key discourses in the field reviewed. This allows more specific issues relating to digital divides and the role of decision-making to follow, introducing the reader to the conceptual framework and research scope of this chapter with regard to the case of Greek divides. The chapter then reports briefly on major methodological issues, as well as on the findings obtained from in-depth individual interviews of elite actors in the Greek Information Society. It is worth noting that, due to space limits, this chapter provides an overview only of the interview findings, with the discussion being by no means exhaustive. Nevertheless, it aims to provide the ground where further research on some of the issues at stake will be conducted. It concludes with an overview of the argument supported throughout and with information about the next phases of the research.

\section{Digital divides: new divides, new discourses and emerging research challenges}

\subsection{Digital divides: an overview}

The digital divide is arguably an "umbrella concept" that traditionally "describe unequal access to technologies or digital exclusion at an international as well at a local level" [5]. Other scholars [25] define digital divides in rather broad terms as "the uneven spread of the new media". On the other hand, the OECD has offered a more elaborate understanding of digital divides, underlining the fact that behind digital divides there is a range of "interlocking divides":

"The importance of ICT to both economic and social development explains the priority of bridging what has come to be known as the 'digital divide'. This is, in fact, a whole series of interlocking 'divides' - the gaps that separate segments of society as well as whole nations into those who are able to take advantage of the new ICT opportunities and those who are not" [32].

On the basis of the above OECD definition, digital divides can be understood as a complex phenomenon that relates not only to access to and use of new information and communication technologies (ICTs) and of the products provided through them, but also to the social, economic, and political contexts where technology is used and developed. This definition attempts to contextualize the phenomenon of digital divides, illustrating not only its complexity but also its various explanations. Nevertheless, no absolute and complete definition of the phenomenon exists, since "the problems of the digital divide have been and probably will continue to be moving targets" suggesting that "the term's definition should be similarly mobile" [16].

Beyond purely definitional terms, digital divides have been a shifting area of research [8] and there is controversy about both the extent of their existence and 
their features: "[t]he 'digital divide' is one of the most discussed social phenomena of our era. It is also one of the most unclear and confusing. What after all is the digital divide" [47]? Others [2,6] wonder whether the term digital divide has a real meaning, when "digital" refers to a range of technological artefacts, goods, contexts, services, applications, etc.

The initial literature on digital divides stresses technological advances or inequalities as resulting in racial employment balances [1], whereas others have discussed digital divides with respect to ICTs in general $[41,12]$. On the other hand, the term "divide" per se implies a strict dichotomy represented by the "all or nothing' scenario" [16] and the "social stratification" [47] approach. Scholars have recently and increasingly criticised this dichotomy arguing that it lacks "sufficient sociological sophistication" [48].

Due to the complexity of digital divides and the importance they hold for this chapter, the discussion that follows attempts to deliver a more insightful discussion of digital divides in conceptual, research, and pragmatic terms.

\subsection{Digital technologies \& divides: beyond access and use?}

In March 2007 less than 17\% of the world population were Internet users [21], suggesting the persistence of digital divides globally. Does this figure constitute the only aspect or element of digital divides?

Primarily conceived as unequal access to indispensable resources, digital divides have drawn researchers' attention to dichotomous socio-economic and demographic differences as the main source of divisions. However, empirical surveys, commentaries on empirical findings, and other scholarly works $(30,31$, 29, 20, 45, 49, 44, 23] have provided contrasting findings with regard to existing inequalities and the role of demographics.

In an attempt to overcome the simplistic "bipolar societal split" between haves and have-nots - or users and non-users - Warschauer [46] demonstrates the meaningful role of physical, digital, human, and social resources in posing barriers that hinder equal access to and use of new information technologies. As far as Internet technologies in particular are concerned, although "social divisions in internet access continue to exist" [50], skills, abilities, breadth of online activities, means of overcoming potential barriers to functional use, as well as the "technoculture" [41] are also among the increasingly important parameters of divides that we should look at. Others argue about the relative and graduated differences between users and non-users, deriving from structural inequalities in skills for and usage of ICTs $[17,38]$. These arguments are closely linked in turn to the issues of "cohort" and "awareness" that Katz and Rice [22] sharply identify as other divides. Moreover, the term "competency", implying technological and educational skills in the use of ICTs, has been looked at the literature, while Silverstone and Haddon [42] have shown that these skills are strongly dependent upon individuals' goals of use and their disposable time/temporal capital among other factors at work. 
Drawing on the necessary parameter of contextualization, we see that digital divides are not just inequities in technological facilities deriving simply from socio-economic inequalities. They also relate to informational gaps that stem from contextual settings which intensify existing socio-economic inequalities, thus creating significant psychological parameters that matter [7]. In an ethnographic study of 20 single-parent and 20 elderly households, Haddon [18] argues that not only the evident financial constraints but also everyday routine, limited sociability, and the pressing limitations of daycare restrict single-parents' understanding of media utility. Likewise, the same study finds that the elderly are marked by unwillingness to familiarize themselves with ICTs, and that, due to their limited past experiences of ICT use, they do not see ICTs as good value for money.

By critically reviewing the above facets of digital divides, this chapter explores Internet adoption as one of the critical aspects of digital divides in Greece. It explores Internet adoption in Greece by conducting an empirical examination of the political and regulatory context of Internet adoption in the country. Internet adoption plays a leading role in the development of digital divides overall, while at the same time allowing other forms of digital inclusion and participation to be looked at. In terms of contextualization, this chapter contends that the Internet is an inseparable part of social life, while Internet adoption is tightly linked to political and regulatory parameters in the field, as discussed below in Section 2.3.

\subsection{Digital divides and interaction with policy and regulation: a forward-looking proposal}

How do digital divides relate to policy and regulation?

The role of politics in digital divides is well illustrated by the debate between defenders and opponents of the welfare state model. This debate constitutes part of the recent discussion about the deconstruction of the legacy of the welfare state under the imperatives of liberty and independence [3]. In contrast to neo-liberal views that support de-regulation, there continues to be literature that argues that the state has a significant role to play in technological innovation since it significantly influences the availability of resources, the establishment of legal frameworks, and the development of investments [27]. On the other hand, the necessity of control by the state has become problematic, since popular discourses perceive the democratic potential of the Information Society as clearly serving market goals, competitiveness, and trade [26]. This debate acquires new interest as social rights and services go hand-in-hand with communication-related issues such as "media access, public service broadcasting, universal telephone service, trade and investment of global telecommunications, media education, and cultural identity" [28]. In this regard, communications influence the parameter of societal inclusion, with the latter posing further challenges to policy setting and regulation making [19].

Departing from the above theory-based discourses, the following OECD indicators illustrate how digital divides are commonly measured: access lines and 
channels, mobile and Internet subscribers, broadband subscribers, availability of Digital Subscriber Lines (DSL), households with access to the Internet and to a home computer, Internet penetration by size class; Internet selling and purchasing by industry, telecommunication services revenue, telecommunication infrastructure investment, R\&D expenditure, trade in ICT goods, contributions of ICT investment to GDP growth, top 50 telecommunications firms and IT firms ${ }^{l}$. Also, in the annual OECD IT Outlook series [37, 36, 34] countries with completely different socio-economic, political, and cultural characteristics are compared mostly in terms of technological and market development.

From the above list, it is evident that the Internet is considered the key technology in the Information Society and that emphasis is placed on market indicators of development. What seems to be missing from the above list are indicators that relate to the ways in which socio-cultural and decision-making mechanisms respond to the rapidly changing technological environment. The lack of "institutional and cultural analyses" [4] seems to deprive research of the potential to provide a fuller picture of the mechanisms that determine the course of new digital technologies and of the Internet in particular in multiple contexts. In addition, the currently missing societal perspective would allows us to look, in Preston's [40] words, at significant implications "for public policies and strategy... which may serve to challenge or enhance the kinds of thinking and considerations that currently inform policy decision-making or practices". These implications relate to the mission of policy and regulation to coordinate the mediation process with a view to shrinking divides between the communicator, the medium, the receiver and the circulation of content.

On the one hand, policy is at the centre of the discussion about the deconstruction of the welfare state legacy under the imperative of liberty and independence [3]. In the media and communications literature, policy has mostly been looked at from a political economy perspective (Melody, Mansell, Garnham, Smith and others), although recently Garnham's work introduced some cultural considerations to the field. This chapter argues that the focus needs to be not so much on the power relations behind institutional- and political economy-centred mechanisms of the policy-making processes, but rather on the ways in which such mechanisms reflect and correspond to society's needs on the basis of what "products" a policy delivers. This is attempted to some degree by Mansell [25] in the discussion of digital entitlements and empowerment of people, where she argues that social needs and cultural differences do not inform media policy to the extent they should, as policy is surrounded by a rhetoric that addresses the digital economy vision resulting in persistent digital gaps between citizens.

Regulation, on the other hand, is a rather technical and complicated area of activity that has little to do with welfare or with neo-liberal policy ideologies and social policies. Empirical studies in media and communications critically discuss

\footnotetext{
${ }^{1}$ A full list of the 15 ICT indicators used in OECD standards to measure the Information Society can be found at www.oecd.org/sti/ICTindicators.
} 
regulation mostly with respect to how it jeopardizes ordinary people's interests and it favours the market. The debate between "citizens" and "consumers" in relation to market competition, public interest, and the state illustrates the controversy between civil society and the market, as well as the rather unclear role of media and communications regulation [24]. The question "citizen and/or consumer" goes beyond rhetoric and attempts to capture whether ordinary people are identified with the market and the consumer's interests or distinguished on the basis of regulatory provisions for inclusion, participation, and citizenship.

On the basis of the above critiques of the role of policy and regulation in digital inclusion, this chapter aims to explore the role of policy and regulation in Greek divides. However, no specific aspects of policy and regulation are to be explored, as this chapter looks at policy and regulation in a rather open way and on the basis of a constantly evolving and complex framework that carries different weight for different actors in the Information Society. The following section introduces the interest that the case of Greek digital divides presents, and the role of policy and regulation.

\section{Case-study of Greece}

Why are Greek digital divides an interesting case to study?

Greek digital divides are understood in this chapter as the persistently low Internet adoption in Greece. For the purposes of the chapter, I aim to briefly discuss political, regulatory, and technology penetration characteristics of Greek divides, so that the importance of this case and the ways in which it fits the conceptual and research framework of the chapter are illustrated.

In political and regulatory terms, the Greek government started to liberalise and privatise the broadcasting and telecommunications market in the early 1990s. So far, the Greek governmental and legislative authorities are not willing to let market forces act freely. Indicative of this is the fact that in January 2006 the European Commission (EC) sent a formal request to Greece asking for information regarding its compliance with the Court of Justice $(\mathrm{CoJ})$ ruling of 14 April 2005 with respect to the country's failure to implement the liberalisation of electronic communications by the established deadline. In addition, the report published by the OECD on regulatory reform in Greece demonstrates the culturerelated difficulties that the authorities of the country face in shaping the Information Society: "although most Greeks will benefit from regulatory reform, the resistance of many protected groups to needed change is hard to overcome" [33]. The OECD pays particular attention to existing administrative barriers [33] and to the tight state control of the economy and of the supposedly independent regulatory process as factors that obstruct regulatory reform and the creation of a competitive telecommunications market in Greece [35]. The OECD therefore highlights the need for "structural change" [35] which supports the criticisms in the literature that the introduction of ICTs has been driven by the private sector while the public sector is lagging behind [43]. 
In terms of technology penetration indicators, Greece has long been slow in the diffusion of network technologies and services. On the basis of the Information Society indicators set by the eEurope and i2010 initiatives, the latest national survey reports uneven diffusion of various types of digital technologies in Greece [14]:

1. In 2006, DVD penetration was $71 \%$ and electronic games console penetration was $26 \%$;

2. An increase was recorded in the possession of desktop computers, from $39 \%$ in 2005 to $42 \%$ in 2006, as well as in portable computers (laptops) from $11 \%$ in 2005 to $16 \%$ in 2006 ;

3. Palmtop computers are still at the same very low level, only $2 \%$, as in 2005;

4. Household access to the Internet increased from $24.2 \%$ in 2005 to $27.4 \%$ in 2006;

5. Terrestrial digital television shows a low penetration, at $8 \%$ in the regions of Attiki, Thessalia and Salonica (where the required infrastructure exists);

6. Awareness of terrestrial digital television is at low levels, with only 2 out of 10 people being aware of it; and

7. One half of the Internet users who are mobile phone users possess a mobile which can connect to the Internet.

Beyond the above general figures, the 2005 national survey of new technologies usage [15] illustrates the increasing penetration of ICTs in Greece for the years 2001-2003 and the stagnation of new technology adoption for the years 2004-2005. Indicatively, in 2005 the five-layered indicator of new technology use increased by only $0.3 \%(13.6 \%)$, whereas the percentage of the population not using new technologies decreased by $2.7 \%$ [15]. Moreover, Internet use in the general population increased in $2005(24.6 \%)$ only by $0.1 \%$ compared to 2004 $(24.5 \%)$ while still being lower than in 2003 (25.2\%). Computer use decreased from $34.2 \%$ in 2003 to $32.2 \%$ in 2004 and increased from $32.2 \%$ in 2004 to $34.3 \%$ in 2005 [15].

Even when looking at Greece in a broader European context, one can see that fundamental Internet indicators, such as Internet adoption and use, remain at surprisingly low levels. More specifically, in the Eurobarometer survey of 2005 [11] Greece is at the very bottom of the EU25 Internet use list, with only 24\% of the population using the Internet. Spain and Italy are far closer to the EU-25 average (49\%), with Portugal having the next lowest percentage (27\%) after Greece ${ }^{2}$.

How does policy and regulation account for the above delays in Internet technologies adoption in Greece? From a regulatory perspective, telecommunications regulation in Greece has been marked by a long history of delays and inconsistencies. According to the 10th EC report on the implementation of the EU Electronic Communications Regulatory Package [10],

\footnotetext{
${ }^{2}$ Internet usage in the EU25 ranges from $85 \%$ in Netherlands to $24 \%$ in Greece [11].
} 
five countries, among which Greece, had not implemented the framework one year after the deadline. As a result, the Commission launched infringement proceedings for non-notification, and proceedings were pending before the European Court of Justice against Belgium, Greece, and Luxemburg [10]. This is an instance that gives support to the idea that, regardless of the globalization trend in regulation, national state strategies and dynamics should not be underestimated [39].

Hence, the chapter looks at the case of Greek divides from an Internet adoption perspective and takes into consideration the fact that "societal change takes more time. It requires organisational changes, a shift in mindsets, modernization of regulation, different consumer behaviour, and political decision" [9]. Aiming to explore the role of decision-making mechanisms in the case of Greek digital divides, Section 4 reports on the methodology applied and the findings obtained from in-depth interviews with twelve elite actors in the Greek Information Society.

\section{In-depth interviews with elite actors in Greece: methodology and key findings}

This section presents the methodology applied and some of the findings obtained from in-depth individual interviews of twelve elite actors in the Greek Information Society. These interviews aimed to trace the major factors that affect the development of the Internet in Greece, particularly in connection with the processes through which policy and regulation are established. Section 4.1 provides some methodological insights on issues of sampling and interview perspective. Section 4.2 presents the main interview findings, pointing to the implications for further research.

\subsection{Sampling: Expertise and interview perspectives}

Twelve interviewees were selected by ordering a list of key policy, regulatory, activist, and research bodies in the Greek Information Society. Members of those bodies who play a role in ICT dissemination activities were contacted and some of them were selected and interviewed. Table 1 presents the interviewees' expertise, as well as the three different interview perspectives adopted during interviewing. 


\begin{tabular}{|c|c|c|c|}
\hline \multirow{2}{*}{$\begin{array}{l}\text { INTERVIEW SAMPLE EXPERTISE } \\
\text { Policy \& Regulation } \\
\end{array}$} & \multicolumn{3}{|c|}{ INTERVIEW PERSPECTIVE } \\
\hline & $\begin{array}{c}\text { Scope } \\
\text { interviews }\end{array}$ & $\begin{array}{c}\text { Bottom } \\
\text { up }\end{array}$ & $\begin{array}{l}\text { Theory } \\
\text { driven }\end{array}$ \\
\hline $\begin{array}{l}\text { Special Secretary of the Operational Program } \\
\text { 'Information Society' (OPIS) in Greece }\end{array}$ & $\square$ & & \\
\hline $\begin{array}{l}\text { President of the National Committee for Electronic } \\
\text { Commerce \& General Secretary of Commerce }\end{array}$ & $\nabla$ & & \\
\hline $\begin{array}{l}\text { Director of Telecommunications, Hellenic } \\
\text { Republic National Telecommunications and Post } \\
\text { Commission }\end{array}$ & $\square$ & & \\
\hline Officer of the EC DG Information Society & $\nabla$ & & \\
\hline Research & $\begin{array}{c}\text { Scope } \\
\text { interviews }\end{array}$ & $\begin{array}{l}\text { Bottom } \\
\text { up }\end{array}$ & $\begin{array}{l}\text { Theory- } \\
\text { driven }\end{array}$ \\
\hline $\begin{array}{l}\text { The Head of Research and Development in the } \\
\text { SafeNetHome Project (Safer Internet Action Plan) } \\
\text { in Greece }\end{array}$ & & & $\nabla$ \\
\hline $\begin{array}{l}\text { Associate Professor and Head of Broadband } \\
\text { Wireless \& Sensor Networks at the Athens } \\
\text { Information Technology Institute (AIT) }\end{array}$ & & & $\square$ \\
\hline Associate Dean, AIT & & & $\square$ \\
\hline Internet Bodies & $\begin{array}{c}\text { Scope } \\
\text { interviews }\end{array}$ & $\begin{array}{l}\text { Bottom } \\
\text { up }\end{array}$ & $\begin{array}{l}\text { Theory- } \\
\text { driven }\end{array}$ \\
\hline $\begin{array}{l}\text { President of the 'Association of Greek internet } \\
\text { Users' (EEXI) }\end{array}$ & & $\nabla$ & \\
\hline Legal Consultant of EEXI & & $\square$ & \\
\hline $\begin{array}{l}\text { President of SAFENET (the Hellenic self- } \\
\text { regulation body) and SAFELINE (the Hellenic } \\
\text { Hotline) }\end{array}$ & & & $\nabla$ \\
\hline $\begin{array}{l}\text { Auditor, Hellenic Data Protection Authority } \\
\text { (DPA) }\end{array}$ & & & $\square$ \\
\hline Market & $\begin{array}{c}\text { Scope } \\
\text { interviews }\end{array}$ & $\begin{array}{c}\text { Bottom } \\
\text { up }\end{array}$ & $\begin{array}{l}\text { Theory- } \\
\text { driven }\end{array}$ \\
\hline $\begin{array}{l}\text { Officer of the Federation of 'Hellenic Information } \\
\text { Technology \& Communications Enterprises' and } \\
\text { Product Manager of FORTHnet }\end{array}$ & & $\nabla$ & \\
\hline
\end{tabular}

Table 1: Interview sample and interview perspective.

The interviews were of three types: scope, bottom-up, and theory-driven. For scope interviews, which emphasize the scope and focus of the research, four interviewees from the broader policy and regulation domain in the Greek Information Society were selected. All four interviewees were in a position to report on the Information Society in Greece, while representing some of the official decision-making authorities of the country. For bottom-up interviews, which emphasize issues that derive from the web of social actors, three interviewees were selected. All three were actors associated with Greek society in general and with the community of Greek Internet users in particular, reporting 
thus on digital divides in Greece from the perspective of their grassroots connections. For interviews led by theory, which emphasize issues deriving from the literature, five interviewees were selected. All five were actors in research areas related to the benefits, risks, and implications of Internet adoption and to the ways in which Greek society perceives such benefits, risks and implications.

The above categories of interviewees cover the field of experts in the Greek Information Society, whilst their classification into three interview categories allows the study to examine all issues of interest from more than one perspective. For instance, the interviewees in the category of "scope" interviews represent the official political and regulatory authorities in the field, whereas the interviewees in the "bottom-up" category raise their voices with respect to societal aspects of digital divides. Lastly, the interviewees categorised as "theory-driven" are actors with an insight stemming mainly from contemporary research on digital divides.

\subsection{Critical overview of findings}

This section presents the interview findings and highlights their implications for future research. In general, complex interconnections between societal and decision-making forces in the Greek context came to the fore in the interviews and significant remarks for the evolution of the Greek Information Society were made regarding the ideology-power complex. I present the findings in relation to the following themes of interest: the Information Society and the Internet in Greece, the public and the Greek Information Society, Internet policy and regulation in Greece, other social forces at work, and points of reference.

\subsubsection{Information Society and the Internet in Greece}

The first theme looks at the Greek Information Society and its main characteristics. The interviews confirmed the empirically demonstrated low level of Internet adoption in Greece, argued about "Greek distinctiveness", and pointed in particular to the liability of the country's political authorities:

"...we are talking about the diffusion of broadband services in Greece, the Internet, and what we actually see when TV cameras go to Ministers' offices is the picture of Jesus Christ because it is this that 'sells', whereas we have not seen any picture of a laptop on Ministers' desks to show that the Minister uses new technologies himself" (Associate Dean, AIT).

The interviewees added to the knowledge base of the study insight into the critical role that specific features of the Greek public administration have played. They interviewees mainly referred to regulatory delays and lack of modernisation and dominance of bureaucracy in the Greek public administration, with the latter being marked by inefficiencies, failures, and highly techno-phobic culture and practices. The inefficiency and lack of modernisation in the public administration in Greece is argued by the Special Secretary of the Operational Program Information Society (OPIS), who manages the political initiatives taken in the 
Information Society, having an insider's view of the Internet decision-making in Greece:

“...the lack of previous experience in promoting new technologies contributes to the persistent difficulty with respect to the harmonious cooperation of the public authorities in charge and to the drawing of a common policy line on the Information Society... Besides, the timeconsuming bureaucratic processes in the country as well as the lack of modernisation of public administration are important barriers to the timely and efficient implementation of the Information Society program."

The interviewees resorted mostly to bibliographic and research sources when making their arguments about socially unaccountable, bureaucratic, inefficient, and non-technocratic decision-making in the country. Actors involved in ICT research, such as the Head of Broadband Wireless \& Sensor Networks and the Associate Dean at the AIT, brought up examples where the bureaucratic operation of the public administration in Greece accounts for the policy and regulation failures in the Greek Information Society:

"These [regulatory delays] are very indicative of the dominant bureaucratic mechanisms in our country, although we are not being affected by it as we are used to be... bureaucracy in Greece is much greater than in other countries and thus... one of the reasons is the lack of penetration of electronic means and services in the public sector ...in order for a draft of legislation to be signed, ten signatures must be collected. It could be electronic signatures so that it takes just one day. However, now, just the signing of draft legislation takes two months in Greece” (Associate Dean).

“...why are we talking about broadband...since politicians themselves do not perceive the benefit of e-services, how can we contribute to their diffusion" (Head of Broadband Wireless \& Sensor Networks)?

It is also worth reflecting on the authorities' own evaluation of how they are structured and operate. Here, we can find references to the lack of collaboration between authorities, to absence of formal and systematic campaigns for public awareness-raising, and to the limited and socially dissociated scope of activities and services provided by the authorities. Indicative are the words of the Auditor of the Hellenic Data Protection Authority (DPA), who indirectly points to the directions where the authorities in charge should improve and work more in:

(Auditor of the Hellenic DPA): "...the truth is that we are very few auditors working here. This is a problem that will hopefully be solved shortly. A second problem is that, at least technically and beyond the law, we do not have the necessary means to carry out extensive audits, to explore the operational systems in depth and to use advanced technical tools. 
Interviewer: However, do you participate in joint actions with other policy and regulatory bodies in the country?

(Auditor of the Hellenic DPA): I would not say that we participate and collaborate in such a way. We collaborate with other bodies only in some cases. Eeem...but there is no particular and regular cooperation line that we follow. For example, we were asked to legislate in order to implement the EU Privacy Directive and there was no collaboration developed from our side with any other authority.

Interviewer: ... and what about the interest in increasing people's awareness about how to protect their personal data on the Internet?

(Auditor of the Hellenic DPA): You know.... if we are talking about information provided to people... eeem... I would not say that. There is no particular awareness campaign carried out by us, something that we know we should promote further. Eeem...as people are interested in that as well. For example, last year...in our annual report these issues were mentioned, and when the DPA President announced our report the public was pretty interested in it..."

On the other hand, market-players in the field emphasize the phenomena of the lack of modernisation and the traditionalism in the Greek public administration sector. Of particular interest is the argument made by the Officer of Federation of Hellenic Information Technology \& Communications Enterprises (SEPE) about people's unwillingness to use new technologies such as the Internet in the public administration sector:

“...unlike what happens in other European countries where policies are vertical, straightforward, clear, and mandatory for the stimulation of Internet use in every field of social life...in Greece there is no such functionality of policy and regulation making on the Internet...this is due to the 'old-fashioned' identity of the Greek public sector which has not become modernised enough, as well as because of the reluctance of governors to promote the Internet as a tool for the necessary modernisation of public administration."

Thus, even the interviewees who are not directly linked to the decision-making mechanisms mentioned particularities concerning attitudes, traits, and cultures in the Greek public sector in order to explain the drawbacks of the country's Information Society. In essence, the interviewees highlighted a research area that has been hugely overlooked in the relevant research conducted in Greece, whilst they approached cultural traits and attitudes to new technologies as matters that go beyond the boundaries of ordinary people's everyday living. 


\subsubsection{The public \& Internet policy and regulation in Greece}

Beyond general trends and characteristics of the Greek Information Society, the interviewees made proposals regarding the establishment of appropriate societal and political conditions that will diffuse new technologies in Greek society. More specifically, they claimed that decision-making in Greece needs to be more socially accountable. The Special Secretary of OPIS described the deeply rooted weaknesses of the decision-making process in Greece in the following way:

"Practically speaking, we design all our future activities in accordance with existing social concerns and needs... This, however, cannot happen through marketing or any such kind of promotion of our efforts. Instead, we decided to act more drastically and practically in order to come closer to the citizen through making decisions and designing policies that would have a practical impact on citizens' everyday lives... we want a more socially-accountable policy on the Information Society that will identify the different needs and demands of different groups of people in society". ${ }^{3}$

This brings to the fore the importance of awareness raising and incorporation of the Internet in citizens' everyday life, as well as the contribution that policy and regulation can make accordingly. The Director of Telecommunications at the National Regulatory Authority argues in this respect:

"I think that what would be very stimulating for the Internet in Greece - this is besides something that I believe at the personal level as well - is e-government, so that citizens get familiarised with online services and realize the benefit of those services. I am afraid that the public sector is still very behind. We are talking about infrastructures and wires, but citizens need to come across new, useful, and important for their everyday lives online public administration services."

These arguments importantly support the notion of "sociology of policy and regulation", while the role of the appropriate IT education is further underlined. Those working in education and awareness-raising research initiatives pointed to the remedial role that education and training in the safe and beneficial use of the Internet can play. Interviewees such as the Head of Research and Development at the SafeNetHome Project, underlined the negative impact that the current lack of thorough IT training and education in Greek schools has on Internet adoption and safe use of the Internet in the country:

\footnotetext{
${ }^{3}$ In this conceptual framework, the Special Secretary of OPIS evaluated regulation. He argued that societal forces have not been taken into account by the authorities of the country and mostly by the previous government:

"Special Secretary: The main mistake is that local particularities have not been taken into account. Interviewer: Have you, therefore, identified a lack of social considerations in the designing of policy and regulation on the information society?

Special Secretary: There used to be such a lack".
} 
“...we do invest a lot in education... it is just unacceptable that there is no computer or Internet training in primary schools in Greece. At the age of 12 and 13 it is already too late to teach a child... what we propose is training about computer and Internet use from the age of 6 , when the child goes to primary school for the first time... parents have to be more informed about the Internet too..."

However, the question about the interface between politics and society and how their interaction can be explained on the basis of interdependency and complexity has been largely left unanswered by the interviewees. By mostly representing elite bodies of action in the Information Society, the interviewees viewed the solution to digital divides as coming from the political and regulatory fields of action, while they expressed the view that the public in Greece lacks citizenship being thus unprepared to drive change. The Officer of the EC DG Information Society and one of the official EU regulatory voices in the Information Society maintains that the society of ordinary people in Greece is hugely inactive, arguing that this as a distinct Greek phenomenon that leads the Greek society to playing no role in decision-making:

"In other countries and mainly in the Anglo-Saxon and Scandinavian counties there are civil societies which are organised in such a way that active civil teams come to existence, take measures and communicate with the public authorities, protect citizens' rights and consumers' rights, etc, etc... In Greece the characteristic of atomism is socially dominant and therefore collective social action is far less existent."

When the interviewees were asked about the possible immediate contribution of society to decision-making, most supported a top-down approach. Even elite actors who aim to increase public awareness of the Internet failed to see the contribution that ordinary people can make through participating in the overall decision-making process. It comes as a surprise that those who argued in favour of more socially-accountable processes do not find any space for citizens to actively participate in decision-making, challenging somehow the idea of participatory democracy. Indicative are the words of the Head of Research and Development in the SafeNetHome Project, who aims to increase awareness of the Internet in the Greek society through promoting the Safer Internet Programme:

"Interviewer: Do you think, however, that Greek civil society may have a role to play in regulation and policy making on the Internet?

Head of Research and Development in the SafeNetHome Project: ...no... I am afraid... how can society participate? ... society is not interested... I don't think that at the moment there is a potential for social action. It is something like a chain... people need to get more interested and stimulated about the Internet first..."

Only the Director of Telecommunications at the National Regulatory Authority placed some emphasis on the catalytic role of public consultations in decision- 
making. This elite actor pointed to the persistent gap between the public and decision-making and provided an alternative to the top-down solution that most of the interviewees proposed:

"Public consultations is a practice that was given particular attention in the last four-five years in order for the unlimited registration of the opinions and proposals of all involved parties to be achieved. Therefore, participants can be enterprises and telecommunications services providers, consumer bodies, as well as everyday people and individual consumers. In general, there is no limitation on who is eligible to participate."

These arguments acquire even more importance since the public was considered by the interviewees to be the ground where politics is based and political culture is shaped. This contradiction indicates that the professional status and profile of the interviewees and the resulted power-ideology complex significantly determine the thread between cause and solution with respect to digital divides in Greece and as this is perceived by the elite actors in the country. Whereas they considered societal forces important, they mostly see change as stemming from policy and regulation and less from the dynamics lying in the web of social activity and mobilisation.

\subsubsection{Other social forces at work}

The above contradiction becomes even more obvious in the fourth theme where the interviewees pointed to the additional role that market development and continuous education can play in the development of the Internet in Greece, while criticizing the role that media propaganda has played in the dismissal of new technologies by the majority of people in Greece. Media propaganda and negative advertising of the internet on TV were regarded by market-players in particular as key factors that enhance negative social attitudes to the Internet, leading thus the interviewees to strongly pessimistic theses as far as the role of citizens in closing digital divides in concerned:

"...we constantly see the media presenting the Internet in a negative way. For example, child pornography and some occasional incidents of suicide on the Internet are presented by the media much more extensively than the benefits of the Internet. We believe that this contributes significantly to social fear, obscurantism, and ignorance about the Internet" (Officer of SEPE).

Additionally, pragmatic factors that influence Internet adoption in Greece, such as a lack of sufficient infrastructure and of satisfactory online services, high cost of internet services and networks, as well as lack of social action and institutional organisation were all brought up as additional parameters to explain digital divides. This constitutes an important addition to the knowledge base of the study, as these pragmatic factors have not been examined in-detail in the context of the study. Indicatively, the President of the Association of Greek Internet Users 
(EEXI) brings to the fore the high cost of access to high speed Internet as problematic for the broader diffusion of Internet technologies in Greece:

"The problem is that the existing infrastructure hinders the Information Society in our country. The Internet is very expensive...can you find an ADSL connection at a cost of less than 50 Euros per month? Where do we live, in Monaco? The enterprises cannot afford such an amount and ADSL is a technology which, whereas Europe is abandoning, Greece is only now discovering... what research in Greece has shown is not only lack of use but also low quality of use, especially in young age groups..."

\subsubsection{Points of reference}

Finally, the fifth and last theme approached in the interviews takes a rather reflexive approach, shedding light on the role of professionalism and "conflicts of interest" in the interview discourses. For instance, the difficulty that many of the interviewees faced in using a socially accountable language can explain the politically driven recommendations they made and the underestimation of the public's role in bringing about change in the Information Society. In particular, the interviewees who participate in policy- and regulation-making used a politically grounded language in their efforts to explain the current situation and the possible future of the Greek Information Society.

Hence, the liability of the political and regulatory authorities of the country contrasts the elite actors' arguments about the marginal role that civil society can play in decision-making and regardless of their arguments in favour of more socially-accountable policies and regulations in the field. On the other hand, culture seems to be lying both in politics and society, bringing up issues of bureaucracy, non-modernisation, and techno-phobia as critically important for the course of digital divides in the country and establishing a rather complex picture of mindsets and practices in decision-making procedures. These findings also highlight the need for further research in order this complexity to be disentangled.

\section{Concluding remarks}

Overall, this chapter aims to illustrate that we cannot view technological innovations as an autonomous field of life and work. It argues that decisionmaking in Greece has a role to play in the digital divides in that country.

This chapter goes beyond problematic accounts of Internet access and use, as it explores Internet adoption and digital inclusion by looking at decision-making in the field. Also, although other digital technologies could be looked at and various other perspectives could be taken into consideration (physical resources, infrastructure, digital resources, applications and content, human resources, education, etc), this chapter looks only at decision-making, namely policy and regulation, as both influencing and being subject to today's rapidly changing digital environment. 
After reviewing the debates and discourses on digital divides, this chapter briefly presents some of the challenges and implications for policy and regulation making. It then proposes an in-depth examination of the role of decision-making, while attempting, in Section 3, to make sense of this proposal with regard to the case of Greek divides. In Section 4, this chapter reports on the methodology applied and the research findings obtained from interviewing twelve elite actors in Greece.

The discussion of the interview discourses confirms the validity of the underlying links between digital divides and policy and regulation making. The central argument articulated in the interviews is that current decision-making mechanisms in Greek Information Society is characterised by a bureaucratic, traditional, and techno-phobic culture, deterring the development of the Information Society in the country and reflecting, to some extent, cultural traits that dominate the Greek environment overall. Thus, the interviewees argue in favour of socially-accountable policies and regulations in the country, so that the authorities come closer to society and pave the way for broader Internet adoption. However, the elite actors failed to answer questions about how politics can change societal culture and how decision-making mechanisms will represent societal needs and desires properly if not with the active participation of civil society in decision-making. Nevertheless, they highlighted certain aspects of the complex network of ideology and power relations, and they indicated key practices and discourses in the Greek Information Society. In addition, other parameters such as delayed market development, media propaganda, and lack of IT education in Greece complete the complex picture of digital divides in the country. Lastly, discrepancies in the texts concerning the need for more socially-accountable policies and regulations, on the one hand, and the widely neglected role of the public in the closing of digital divides, on the other hand, raise the rhetoric applied by the interviewees.

Although the analysis focused on a rather small number of interview discourses, this chapter provides an insight into the possible interconnections between political, social, and technological factors in the shaping of digital divides, indicating the validity of the conceptual and research framework of the study. The chapter also paves the way for more focused, empirically rich, and exhaustive research in the future, as this research is still ongoing. The next stages of the research consist of a large-scale survey of ordinary people (both Internet users and non-users) in Greece who will provide a bottom-up account of the role of policy and regulation in Internet adoption in Greece and in connection with ordinary people's culture and attitudes towards the Internet. Finally, follow-up focus group interviews, with a sub-sample of surveyed individuals, will conclude the empirical research, aiming both to provide some qualitative depth to the survey findings and to integrate with the data collected in the in-depth interviews with elite actors. 


\section{References}

[1] Angwin, J., \& Castaneda, L. (1998). The digital divide: High-tech boom a bust for blacks, Latinos. San Francisco Chronicle, 4 May.

[2] Brady, M. (2000). The digital divide myth. E-commerce Times, www.ecomercetimes.com/story/3953.html.

[3] Calabrese, A. (1997). Creative destruction? From the welfare state to the global information society. Javnost/The Public, 4(4), 7-24.

[4] Calabrese, A. (1999). Afterword. In A. Calabrese \& J.-C. Burgelman (Eds.), Communication, citizenship, and social policy: Rethinking the limits of the welfare state (pp. 311-314). Lahnham; Boulder; New York; Oxford: Rowman \& Littlefield Publishers, Inc.

[5] Cammaerts, B. \& Audenhove Van L. (2003). Dominant digital divide discourses. In B. Cammaerts, L. Van Audenhove, G. Nulens \& C. Pauwels (Eds.), Beyond the digital divide: Reducing exclusion, fostering inclusion. Brussels: Brussels University Press.

[6] Chaney, H. (2000, March 12, 2000). The US "digital divide" is not even a virtual reality. Bridge News.

[7] Chen, W., Boase, J., \& Wellman B. (2002). The global villagers: comparing internet users and uses around the world. In B. Wellman \& C. Haythornthwaite (Eds.), The Internet in Everyday Life. Oxford: Blackwell.

[8] Compaine, B. M. (Ed.). (2001). The digital divide: facing a Crisis or Creating a Myth? Cambridge; MA; London: MIT Press

[9] EC. (2002). eEurope benchmarking report: eEurope 2002. Brussels. COM (2002) 62 final.

[10] EC (2004). Communication from the Commission to the Council, the European Parliament, the European Economic and Social Committee and the Committee of the Regions. European Electronic Communications Regulation and Markets 2004. COM (2004) 759 final. Brussels, 2.12.2004.

[11] EC (2006). Safer internet. Eurobarometer 203/Wave 250 survey (December 2005 January 2006). Publications: May 2006.

[12] Frissen, V. (2003). The myth of the digital divide. In B. Cammaerts, L. V. Audenhove, G. Nulens \& C. Pauwels (Eds.), Beyond the digital divide: reducing exclusion, fostering inclusion (pp. 17-33). Brussels: VUB Brussels University Press.

[13] Gaskell, G. (2000). Chapter 3: Individual and group interviewing. In M. W. Bauer \& G. Gaskell (Eds.), Qualitative researching: with text, image and sound. A practical handbook. London: Sage.

[14] Greek Information Society Observatory. (2007). Study for measuring the indicators of the eEurope and 2010 initiatives for the years 2006 and 2007. Athens: Greek Information Society Observatory.

[15] GRNet. (2005). National survey on new technologies and the information society. (in Greek). Athens

[16] Gunkel, D. J. (2003). Second thoughts: Toward a critique of the digital divide. New Media and Society, 5(4), 499-522.

[17] Hacker, K., \& Van Dijk, J. (2003). The digital divide as a complex and dynamic Phenomenon. The Information Society, 19(4), 315-326.

[18] Haddon, L. (2000). Social exclusion and information and communication technologies. Lessons from studies of single parents and the young elderly. New Media \& Society, 2(4), 387-406.

[19] Henten, A. (1999). Will information societies be welfare societies? In A. Calabrese \& J.-C. Burgelman (Eds.), Communication, Citizenship, and Social Policy: Rethinking 
the Limits of the Welfare State (pp. 77-90). Lahnham; Boulder; New York; Oxford: Rowman \& Littlefield Publishers, Inc.

[20] Hoffman, D., Novak, T., \& Scholsser, A. (2001). The evolution of the digital divide: Examining the relationship of race to internet access and usage over time. In B. Compaine (Ed.), The Digital Divide: Facing a Crisis or Creating a Myth? (pp. 4798). Cambridge: MIT Press.

[21] Internet World Stats. Usage and population statistics. Retrieved from http: www.internetworldstats.com/stats.htm, [Accessed 10/19/07].

[22] Katz, J., \& Rice, R. (2002). Social consequences of the Internet: Access, Involvement and Interaction. Cambridge, Mass.: MIT Press.

[23] Kirkup, G. (2001). Getting our hands on it: Gendered inequality in access to information and communications technologies. In S. Lax (Ed.), Access Denied in the Information Age. New York: Palgrave.

[24] Livingstone, S., Lunt, P., \& Miller, L. (2007). Citizens, consumers and the citizenconsumer: articulating the citizen interest in media and communications regulation. Discourse \& Communication, 1(1), 63-89.

[25] Mansell, R. (2002). From digital divides to digital entitlements in knowledge Societies. Current Sociology, 50(3), 407-426.

[26] Mattelart, A. (2003). The information society: an introduction. London: Sage.

[27] May, C. (2002). The information society: a sceptical view. Cambridge: Polity Press

[28] Mosco, V. (1999). Citizenship and the technopoles. In A. Calabrese \& J.-C. Burgelman (Eds.), Communication, citizenship, and social policy: rethinking the limits of the welfare state (pp. 33-45). Lahnham; Boulder; New York; Oxford: Rowman \& Littlefield Publishers, Inc.

[29] NTIA. (2000). Falling through the net: toward digital inclusion. US Commerce Department.

[30] NTIA (2001a). Falling through the met: a survey of the "Have-Nots" in rural and urban America. In B. Compaine (Ed.), The Digital Divide. Facing a Crisis or Creating a Myth? (pp. 7-15). Massachusetts: MIT Press.

[31] NTIA (2001b). Falling through the net: Defining the digital divide. In B. Compaine (Ed.), The Digital Divide. Facing a Crisis or Creating a Myth? (pp. 17-46). Massachusetts: MIT Press.

[32] OECD (2000). Learning to bridge the digital divide. Paris: Organisation for Economic Co-operation and Development.

[33] OECD (2001) Greece set to reap maximum benefits from regulatory reform. Paris: OECD.

[34] OECD (2002a). Information technology outlook 2002. Paris: OECD.

[35] OECD (2002b) Regulatory reform in the telecommunications industry in Greece. Paris: OECD.

[36] OECD (2004). Information technology outlook 2004. Paris: OECD.

[37] OECD (2006). Information technology outlook 2006. Paris: OECD.

[38] Perri 6 with Jupp, B. (2001). Divided by information? The "Digital Divide" and the implications of the new meritocracy. London: Demos.

[39] Preston, P. (2001). Reshaping communications: Technology, information and social change. London; Thousand Oaks; CA: Sage.

[40] Preston, P. (2005). ICTs in everyday life: Public policy implications for Europe's way to the information society. In R. Silverstone (Ed.), Media, technology and everyday life in Europe: from information to communication (pp. 195-211). Aldershot: Ashgate.

[41] Selwyn, N. (2004). Reconsidering political and popular understandings of the digital divide. New Media \& Society, 6(3), 341-362. 
[42] Silverstone, R., \& Haddon, L. (1996). Television, cable and AB households. A report for Telewest plc: University of Sussex:, Graduate Research Centre in Culture and Communication.

[43] Voulgaris, Y. and D. Sotiropoulos (2002). Information society, sociology and technology. Athens: Operational Programme for the Information Society. (in Greek).

[44] Walsh, O. E., Gazala, M. E., \& Ham C. (2001). The truth about the digital divide. In B. Compaine (Ed.), The digital divide. Facing a crisis or creating a myth?. Massachusetts: MIT Press.

[45] Walton, A. (1999). Technology vs African-Americans. Atlantic Monthly 283(1), 1418.

[46] Warschauer, M. (2003a). Technology and social inclusion: rethinking the digital divide. Cambridge, Massachusetts: MIT Press.

[47] Warschauer, M. (in press). A literacy approach to the digital divide. In M. A. Pereyra (Ed.), Las mulialfabetizaciones en el espacio digital. Malaga: Ediciones Aljibe.

[48] Webster, F. (1995). Theories of the information society. London: Routledge.

[49] Wilhelm, A. (2001). From crystal palaces to silicon valleys: Market imperfection and the enduring digital divide. In S. Lax (Ed.), Access denied in the information age. New York: Pargrave.

[50] Wyatt, S., Thomas, G., \& Terranova, T. (2002). They came, they surfed and then went back to the beach: Conceptualizating use and non-use of the internet. In S. Woolgar (Ed.), Virtual society? Technology, cyberbole, Reality (pp. 23-40). Oxford: Oxford University Press. 